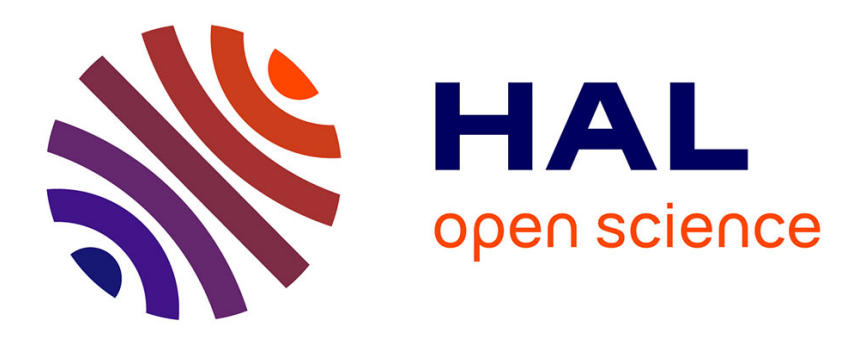

\title{
The role of irrigation in farmer's risk management strategies in France
}

S. Foudi, K. Erdlenbruch

\section{To cite this version:}

S. Foudi, K. Erdlenbruch. The role of irrigation in farmer's risk management strategies in France. European Review of Agricultural Economics, 2011, 39 (3), p. 439 - p. 457. 10.1093/erae/jbr024. hal-00704970

\section{HAL Id: hal-00704970 https://hal.science/hal-00704970}

Submitted on 6 Jun 2012

HAL is a multi-disciplinary open access archive for the deposit and dissemination of scientific research documents, whether they are published or not. The documents may come from teaching and research institutions in France or abroad, or from public or private research centers.
L'archive ouverte pluridisciplinaire HAL, est destinée au dépôt et à la diffusion de documents scientifiques de niveau recherche, publiés ou non, émanant des établissements d'enseignement et de recherche français ou étrangers, des laboratoires publics ou privés. 


\title{
The role of irrigation in farmers' risk management strategies in France
}

\author{
Sébastien Foudi ${ }^{\dagger}$, Katrin Erdlenbruch ${ }^{* \ddagger}$ \\ ${ }^{\dagger}$ Basque Centre for Climate Change (BC3), Bilbao, Spain; \\ ${ }^{\ddagger}$ Cemagref, UMR G-EAU and LAMETA, Montpellier, France.
}

\begin{abstract}
We analyze the way French farmers manage production risks, especially the risk of drought. To this end, we assess the role of irrigation in farmers' risk management. Based on FADN accountancy data, we jointly estimate farmers' attitudes to risk and their production decisions. We correct for sample selection bias and endogeneity. Results of the probit model show that irrigation technology serves as a self-insurance. Results of the joint estimation show that irrigating farmers have higher means but lower variance of profits than non-irrigating farmers. However, for already irrigating farmers, using more water volumes increases the variance of outcome.
\end{abstract}

Keywords: production risk, irrigation, insurance, joint estimation, sample selection. JEL classification: C30, D80, Q12.

Running title: Irrigation and farmers' risk management.

${ }^{*}$ Corresponding author: Cemagref, 361 rue JF Breton BP 5095, 34196 Montpellier Cedex 5, France. E-mail: katrin.erdlenbruch@cemagref.fr 


\section{Introduction}

It is common knowledge that irrigation water increases agricultural yields. Irrigation is also supposed to decrease the variability of yields, and hence the variability of income. But, empirical evidence of this is rare. One reason is that irrigation comes at a cost: owning irrigation technology is expensive, and this may offset the impact of increases in yields. In addition, crops that require irrigation may react less easily to extreme climatic events, which in turn may increase the variability of yields and income. On the other hand, irrigation may trigger additional benefits because it enhances the quality of crops. Vandeveer et al. (1989) showed that irrigation decreased variability of agricultural income in Louisiana, whereas Groom et al. (2008) could not confirm this assumption in their case study in Cyprus.

In this article, we evaluate the role of irrigation in farmers' production processes, taking into account the natural variability of production and the fact that farmers have different attitudes towards risk. One central question of this paper is whether irrigation water is a risk-increasing or a risk-decreasing input. To answer this question, we test the marginal impact of irrigation water use on the distribution of agricultural yield and profit (see Groom et al., 2008). We use an approach in which production and preferences are estimated jointly (see Kumbhakar and Tveteras, 2003), which avoids making any assumptions about farmers' risk aversion. Because we deal with irrigating and non-irrigating farmers, we adapted this approach to be able to deal with endogeneity and sample selection bias, which is the main novelty of our paper.

Another question related to the role of irrigation water in the production process is whether irrigation is used as a self-insurance tool to tackle drought (Amigues et al., 2006). Reynaud (2009) studied the way farmers manage drought risks via irrigation and crop diversification. He showed that for French farmers, crop diversification is more efficient than irrigation in tempering possible revenue losses. In this paper, we expect irrigation to be a common drought risk management tool and model the link between adopting irrigation technology and buying a yield insurance.

We base our analysis on the joint estimation of stochastic production parameters and risk preferences. Early literature on stochastic production functions focused on separate estimations of mean production and production risk parameters. Just and Pope (1978, and 1979) proposed breaking down the stochastic production function into a mean and a variance term, which allowed the effects of inputs on the distribution of outputs to either increase or decrease (see also Vandeveer et al., 1989, for an application). This is one element we take up in this paper. Antle (1983) used an approximation of the distribution of outputs by its moments ${ }^{1}$ and introduced the utility function in the estimation of stochastic production functions, stating that the optimal allocation of inputs depends on both the marginal effect of inputs on outputs and the risk attitudes of the decision maker (Antle, 1987, 1988; Antle and Goodger, 1984; Groom et al., 2008; Amadieu and Viviani, 2011).

\footnotetext{
${ }^{1}$ He showed that Just and Pope's approach restricts the effects of inputs on the higher moments of the output distribution, i.e. the third (skewness) and fourth (kurtosis) moments.
} 
Di Falco and Chavas (2006) expanded Just and Pope's mean-variance approach to analyze the role of crop genetic diversity in the protection of pest control and drought management in Sicily. However, these approaches focus on the analysis of the distribution of residuals and are sequential estimations (see Eggert and Tveteras, 2004). The joint estimation of stochastic production functions and risk attitudes both improves efficiency and ensures consistent estimates (see Love and Buccola, 1991; Shankar and Nelson, 1999), which is the reason we adopted this approach.

More recently, studies turned toward the joint estimation of stochastic production functions and risk attitudes (Antle, 1983; Antle and Goodger, 1984; Love and Buccola, 1991, 1999; Shankar and Nelson, 1999; Zellner et al., 1966). Love and Buccola used such a joint estimation approach but needed to specify a utility function and to assume a normal distribution of errors. Kumbhakar and Tveteras (2003) proposed joint estimation of preferences and technology in a mean-variance model, without specifying a utility function and without making any assumptions on the distribution of the residuals. They also showed how risk coefficients $^{2}$ can be derived and how the type of risk attitudes ${ }^{3}$ can be tested for. Recent applications ${ }^{4}$ include an analysis of European subsidy policies in Finland (see Koundouri et al., 2009). Some most recent studies heavily criticize the above empirical methods, for different reasons. Lence (2009) and Just and Just (2011) for example showed that estimations of the type of risk attitudes in this context are not robust. While Lence (2009) seems to accept estimations of risk coefficients in large samples, Just and Just (2011) claim that imposing any arbitrary specification on production risk or production structure undermines the possibility of global identification of risk preferences (see our conclusion for a more detailed discussion).

Our paper is based on the approach of Kumbhakar and Tveteras (2003) but it corrects for sample selection bias and deals with irrigated agriculture. Of course, previous literature has addressed the problem of optimal irrigation water use: for example Groom et al. (2008) analyzed the use of irrigation water and the impact of water quota policies in Cyprus, using Antle's moment based approach. Koundouri et al. (2006) modeled a farmer's decision to adopt new irrigation technologies in Crete, also using the flexible moment based approach. However, none of these studies used joint estimation of risk attitudes and production decisions. In addition, none of these studies applies to the situation in France.

The paper is organized as follows. In section (2) we present the dataset. In section (3) we describe the theoretical model, both in general, and including irrigation water use. In section (4) we describe the econometric model: the estimation procedure for correcting sample selection and the procedure for estimating jointly stochastic production and risk

\footnotetext{
${ }^{2}$ Arrow-Pratt and Downside risk coefficients can be computed. However, the downside-risk coefficient should be interpreted with caution because the proposed model is based on a mean-variance approach and does not model skewness.

${ }^{3}$ Decreasing absolute risk aversion (DARA), constant absolute risk aversion (CARA), or increasing absolute risk aversion (IARA).

${ }^{4}$ See also Isik (2002) for models including price uncertainties. Here, we consider a short time span with low price variability.
} 
preferences. In section (5) we discuss the results, both concerning the choice of irrigation and yield insurance and concerning the role of irrigation in a risky production process. In section (6) we draw some conclusions and outline new research perspectives.

\section{Data}

Our analysis is based on farm-level production data from the European Farm Accountancy Data Network (FADN, RICA-Agreste). Our dataset comprises 243 observations for corn growers in the years 2006 and $2007^{5}$. The sample comprises the most important corn producing regions in France (see map in figure 1): Alsace, Aquitaine, Midi-Pyrénées, Poitou-Charente and Rhône-Alpes but also Haute and Basse Normandie, Pays de la Loire and Auvergne.

Figure 1: Represented corn-producing regions in France: in dark main producing regions
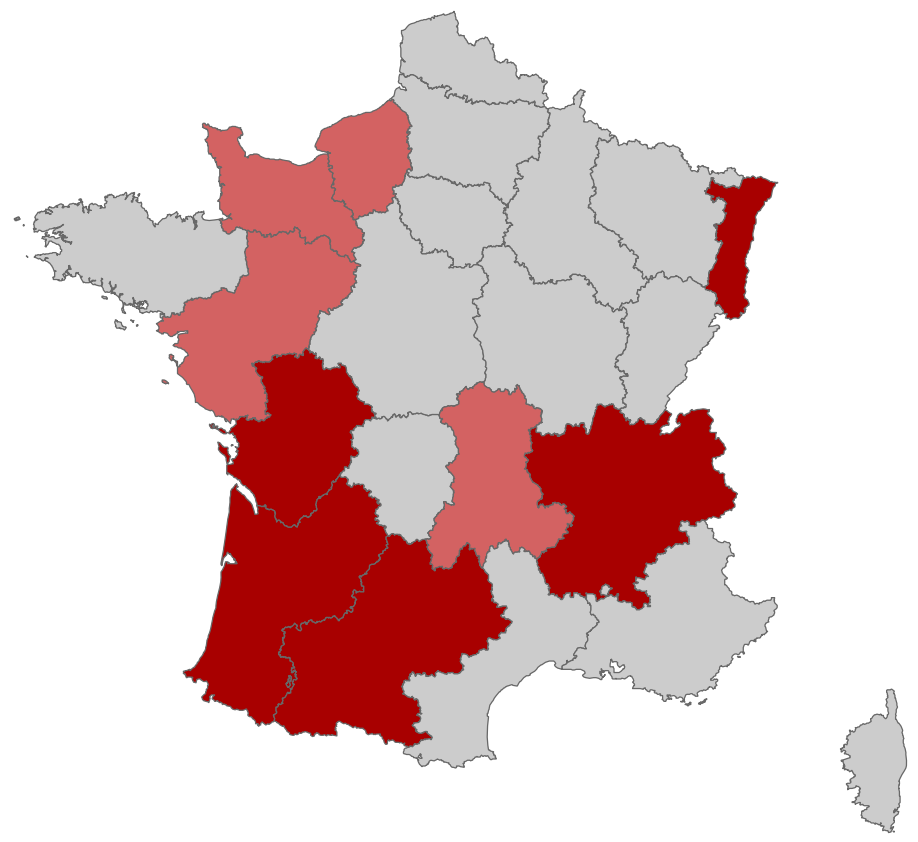

Farmers are specialized in corn production, as most of their margin comes from cereal production $^{6}$ and corn occupies at least $60 \%$ of their cultivated area. This allows us to allocate production costs to corn production, according to the assumption of stochastic nonjointness (see Antle, 1983; Antle and Goodger, 1984). For example, concerning irrigation

\footnotetext{
${ }^{5}$ We use the dataset as a pooled base and not as a panel data. As a consequence, we do not detect individual-specific unobserved effects.

${ }^{6}$ Cereal growers corresponding to TF 13 and 14 in FADN.
} 
water, this assumption means that all irrigation water charges apply to corn production. Our sample confirms that $96.75 \%$ of all irrigated areas are used for corn.

Labor input volume and price were derived from the FADN dataset. The labor price includes salaries for employees and the farmer. Water and fertilizer prices were derived by combining the FADN dataset with the Cropping Practices Survey (CPS) data of 2006 (Enquête sur les pratiques culturales - Agreste). The CPS provides water and fertilizer volumes at the plot level for a sample of corn plots in about 100 geographical zones (French départements). We computed mean input volumes at the departmental level and considered them to be representative of the department. We determined departmental input prices by dividing FADN input charges by CPS input volumes for each department. We then computed individual input volumes (for water and fertilizer use) based on individual input charges in FADN and the above departmental prices. The Meteo-France SAFRAN dataset provides data on rainfall, evapotranspiration and temperatures at a scale of $8 \mathrm{~km}^{2}$ for the whole French territory and for the period 2002 to 2007.

Summary statistics for production and the meteorological context are listed in table 1. On average, farmers use 58 ha for corn production, generating a yield of $10.24 \mathrm{t} / \mathrm{ha} .68 \%$ of the farmers are irrigators, using $1123 \mathrm{~m} 3 /$ ha of water on average, for an input price of $0.07 € / \mathrm{m} 3$. The maximum volume applied is $4714 \mathrm{~m} 3 / \mathrm{ha}$ and the minimum $14 \mathrm{~m} 3 / \mathrm{ha}$. CAP payments amount to $462 € /$ ha, or $26790 €$ for the average surface area, representing over $55 \%$ of total average profits.

We define water availability as the difference between rainfall and evapotranspiration at the commune level ${ }^{7}$. This is what meteorologists call efficient rainfall. We use this variable as a proxy for overall water availability. Throughout our analysis, we consider water availability during the irrigation campaign from mid-May to the end of August ${ }^{8}$, including the crucial growth stage of corn and excluding the period after harvest. For the two-year study period, mean rainfall from mid-May to mid-August was relatively low compared to mean evapotranspiration for the same period (cf. table 1). Mean water availability was thus negative, at $-143 \mathrm{~mm}$. This means that farmers indeed took their production decisions in the context of water deficit, although this is a moderate deficit compared to dryer years and climate. Moreover, standard errors of water availability (72 $\mathrm{mm}$ ) are high, which means that farmers actually did face climatic risks.

Finally, the loss-ratio is defined as the ratio of insurance payments to the insurance premium paid. In the following analysis, we explain the probability to irrigate and the probability of buying yield insurance as a function of different variables. We use the loss ratio as an indicator for expected return from insurance.

\footnotetext{
${ }^{7}$ The farmers in the sample are spread over 137 communes.

${ }^{8}$ Irrigation campaigns have been precisely determined for each department by the help of the CPS dataset.
} 
Author-produced version of the article published in European Review of Agricultural Economics, 2011,39(3), $439-457$. doi: 10.1093/erae/jbr024

Table 1: Descriptive statistics for the variables used in the model

\begin{tabular}{llrr}
\hline Variable & Unit & Mean & $\begin{array}{r}\text { Standard } \\
\text { deviation }\end{array}$ \\
\hline Surface & ha & 57.73 & 37.59 \\
Yield & $\mathrm{t} / \mathrm{ha}$ & 10.24 & 1.88 \\
Price & $€ / \mathrm{t}$ & 153.00 & 33.10 \\
Water* & $\mathrm{m} 3 / \mathrm{ha}$ & 762.77 & 936.19 \\
Fertilizer & units/ha & 108.98 & 54.40 \\
Labour & hours/ha & 54.74 & 40.72 \\
Water price & $€ / \mathrm{m} 3$ & 0.074 & 0.06 \\
Fertilizer price & $€ /$ unit & 1.45 & 0.42 \\
Salary** & $€ /$ hour & 22.14 & 18.17 \\
CAP subsidy & $€ /$ ha & 461.90 & 131.99 \\
Age & years & 48.6 & 8.3 \\
\hline Rain & $\mathrm{mm}$ & 295.89 & 67.78 \\
Evapotranspiration & $\mathrm{mm}$ & 438.69 & 87.98 \\
Water availability*** & $\mathrm{mm}$ & -142.80 & 71.77 \\
Water availability in 2005 & $\mathrm{mm}$ & -224.66 & 69.00 \\
Variance of water availability in 2005 & $\mathrm{~mm}$ & 16.50 & 6.40 \\
Skewness of water availability in 2005 & $\mathrm{~mm}$ & 2.79 & 2.18 \\
Intertemp. mean of income (2002 to 2005) & $1000 €$ & 29.32 & 2.185 \\
Intertemp. variance of income (2002 to 2005) & $1000 €$ & 30.61 & 4.895 \\
Loss ratio in 2005 & $\%$ & 0.53 & 1.25 \\
\hline
\end{tabular}

Number of observations: 243. SAFRAN - Meteo France. RICA - Agreste.

*For whole population. Irrigators only: $1123.35 \mathrm{~m} 3 /$ ha (sd 941.16).** Mean labour price for total population.

*** Water availability is computed from mid-May to the end of August. 


\section{The model}

\subsection{A model explaining production choices in a risky environment}

In this section, we present the model we aim to study. Assuming constant returns to scale with respect to land, the stochastic yield function, $Y$, is broken down according to Just and Pope $(1978 ; 1979)$ :

$$
Y=f(X)+g(X) \varepsilon .
$$

The mean function $f$ depends on the variable inputs $X$ like labour or fertilizer (and irrigation water in the second step). $g$ is the variance function of the yield associated with the random term $\varepsilon$ which represents the exogenous shock on production with $E(\varepsilon)=0$ and $\operatorname{Var}(\varepsilon)=1$. The per hectar profit of the farmer is given by:

$$
\Pi=p Y-r^{\prime} X,
$$

where $p$ is the output price vector (assumed to be risk-free) and $r$ is the input price vector for inputs $X$. Fixed costs and lump-sum subsidies can be neglected at this stage (see Hennessy, 1998; Just, 2011) as they do not impact input decisions (note that subsidies are reintroduced later to measure the size of profits). The farmer's decision problem, under expected utility maximization is:

$$
\max _{X} E U[\Pi]=\max _{X} E U\left[p(f(X)+g(X) \varepsilon)-r^{\prime} X\right] .
$$

The first order condition with respect to each input $x_{j} \in X$ is given by:

$$
\frac{\partial f}{\partial x_{j}}=\frac{r_{j}}{p}-\frac{\partial g}{\partial x_{j}} \frac{E\left[\varepsilon U^{\prime}\right]}{E\left[U^{\prime}\right]} .
$$

The ratio $\frac{E\left[\varepsilon U^{\prime}\right]}{E\left[U^{\prime}\right]} \equiv \theta$ determines risk preferences, independent of inputs, where $U^{\prime}$ is the marginal utility of profit ${ }^{9}$. This ratio is negative for risk averse agents, zero for risk neutral agents and positive for risk lovers. The sign of the derivative $\frac{\partial g}{\partial x_{j}}$ indicates whether the input $x_{j}$ is risk-reducing $\left(\frac{\partial g}{\partial x_{j}}<0\right)$ or risk-increasing $\left(\frac{\partial g}{\partial x_{j}}>0\right)$. Following Kumbhakar and Tveteras (2003), it is possible to break down the risk preference function, $\theta$, depending on the Arrow-Pratt measure of absolute risk aversion $A R$, the variance of profits $\sigma_{\pi}^{2}$, the skewness of the distribution of $\epsilon$ and the measure for the downside risk aversion $D R$. Once a parametric form of $A R$ is assumed, it is possible to derive $D R^{10}$.

\footnotetext{
${ }^{9}$ Like the other variables, risk preferences are specific to each individual, $i$. We have omitted the subscripts in order to improve readability.

${ }^{10}$ According to Kumbhakar and Tveteras, the flexible quadratic form of AR allows testing for CARA, IARA and DARA, respectively: when $\partial A R / \partial \mu_{\pi}=\delta_{1}+\delta_{2} \mu_{\pi}$, is positive (negative) agents are IARA (DARA). This was strongly put into question in the most recent literature, (see Lence, 2009; Just and Just, 2011)
} 


\subsection{A model including irrigation}

Let $x_{w} \in X$ be irrigation water used and $x_{j} \in X$ variable inputs other than irrigation water (i.e. labour and fertilizer) $)^{11}$. Depending on whether the farmer irrigates or not, yield is given by:

$$
Y= \begin{cases}f\left(x_{j}, x_{w}\right)+g\left(x_{j}, x_{w}\right) \varepsilon & \text { if } x_{w}>0 \\ f\left(x_{j}\right)+g\left(x_{j}\right) \varepsilon & \text { otherwise. }\end{cases}
$$

Thus one faces a problem of sample selection with respect to irrigation water. The first order condition with respect to $x_{w}$ is now given by:

$$
\frac{\partial f}{\partial x_{w}}-\frac{r_{w}}{p}+\frac{\partial g}{\partial x_{w}} \theta=0,
$$

if $x_{w}>0$. If $x_{w}=0$, this expression is negative.

For the irrigation water input, $x_{w}$, this arbitrage condition states that the farmer irrigates as long as the marginal product of irrigation water equals its cost-price ratio net of the cost of risk. The cost of risk describes the additional exposure to risk that the farmer faces when using one further unit of irrigation water, according to his risk preferences. For example, when the farmer is risk averse, i.e. $\theta<0$ and irrigation increases risk $\frac{\partial g}{\partial x_{j}}>0$, there is an additional cost of using more irrigation water. When the farmer is risk averse and irrigation decreases risk $\frac{\partial g}{\partial x_{j}}<0$, there is an additional gain in irrigating. Likewise, when the farmer is a risk taker, i.e. $\theta>0$ and irrigation reduces (increases) risk, there is an additional cost (gain) of increasing irrigation.

\section{The estimation procedure}

\subsection{The first step probit model}

In order to correct for endogeneity and censoring in water input choice, we estimate the probability of irrigating for each individual $(i=1, \ldots, N)$, we compute the inverse Mill's ratio for irrigating farmers $\left(i=1, \ldots, N_{1}\right.$, with $\left.N_{1} \subset N\right)$ and we use this ratio as a regressor in the yield function.

More precisely, we use a system of simultaneous equations with a recursive structure (see Maddala, 1983). The probability to irrigate, $\operatorname{Prob}\left(x_{i w}^{*}>0 \mid x_{i j}, Z_{i}, D, z_{i}\right)$, is explained by a set of exogenous variables $\left(Z_{i}\right.$ and $\left.D\right)$ and one endogeneous dichotomic variable, $z_{i}{ }^{12}$. The model reads thus as follows:

$$
\left\{\begin{array}{l}
x_{w i}^{*}=\alpha_{1} x_{j i}+\alpha_{2} Z_{i}+\alpha_{3} z_{i}+\alpha_{4} D+\varepsilon_{w i} \\
z_{i}^{*}=\beta_{1} x_{j i}+\beta_{2} Z_{i}+\beta_{3} D+\varepsilon_{z i},
\end{array}\right.
$$

\footnotetext{
${ }^{11}$ It should be noted that the decision to use irrigation water is different from the decision to adopt a new irrigation technology. For the yield function, we assume irrigation equipment and technology exist.

${ }^{12} Z_{i}$ is a set of individual variables, $D$ is a set of climatic data, $z_{i}$ is measured by the premium paid for yield insurance.
} 


$$
x_{w i}=\left\{\begin{array}{cc}
1 & \text { if } x_{w i}^{*}>0 \\
0 & \text { otherwise, }
\end{array} \quad z_{w i}= \begin{cases}1 & \text { if } z_{w i}^{*}>0 \\
0 & \text { otherwise }\end{cases}\right.
$$

where $x_{w i}^{*}$ and $z_{i}^{*}$ are the latent variables associated to irrigation and insurance respectively. $\left(\varepsilon_{w}, \varepsilon_{z}\right)$ is the vector of bivariate normally distributed disturbances with the restrictions $\operatorname{Var}\left(\varepsilon_{w i}\right)=\operatorname{Var}\left(\varepsilon_{z i}\right)=1$.

We then compute the inverse Mill's ratio $\hat{M} \sigma_{u}=\frac{\phi()}{\Phi()} \sigma_{u}$, where $\phi$ and $\Phi$ are respectively the normal density and the cumulative distribution function of $\operatorname{Prob}\left(x_{i w}^{*}>0 \mid x_{i j}, Z_{i}, D, z_{i}\right)$ and $\sigma_{u}$ is the correlation between unexplained yield and the latent variable of irrigation. This corrects for endogeneity and sample selection bias in the following joint estimation model (see equation 9).

\subsection{The second step system of equations}

The system we consider consists of 4 equations, the yield function and the FOCs for the three inputs, $k=w, f, l$. The yield function is given by:

$$
\frac{y}{g(X)}=\frac{f(X)}{g(X)}+\epsilon
$$

The functional forms are chosen as follows: the mean function is quadratic:

$$
f\left(x_{w}, x_{f}, x_{l}\right)=\sum_{k} \alpha_{k} x_{k}+\frac{1}{2} \sum_{k} \sum_{k^{\prime}} \alpha_{k k^{\prime}} x_{k} x_{k^{\prime}}+\sigma_{u} \hat{M}
$$

while the risk function takes a Cobb-Douglas form:

$$
g\left(x_{w}, x_{f}, x_{l}\right)=x_{w}^{\beta_{w}} x_{f}^{\beta_{f}} x_{l}^{\beta_{l}} .
$$

The FOCs for the three inputs, $k=w, f, l$, are:

$$
\alpha_{k}+\alpha_{k k} x_{k}+\sum_{k^{\prime} \neq k} \alpha_{k k^{\prime}} x_{k^{\prime}}-\frac{r_{k}}{p}+\theta(.) \frac{g(.)}{x_{k}} \beta_{k}=u_{k} .
$$

The risk attitude is determined for each individual in the sample ${ }^{13}$ and is defined by the following equation:

$$
\theta=\frac{-A R \sigma_{\pi}+0.5 D R \sigma_{\pi}^{2} \gamma}{1+0.5 D R \sigma_{\pi}^{2}}
$$

We assume that AR takes a quadratic form as a function of mean profits, $\mu_{\pi}$ :

$$
A R=\delta_{0}+\delta_{1} \mu_{\pi}+0.5 \delta_{2} \mu_{\pi}^{2},
$$

\footnotetext{
${ }^{13}$ The index i has been dropped for clarity of reading.
} 
while DR can be derived from AR as follows:

$$
D R=\frac{-\partial A R}{\partial \mu_{\pi}}+A R^{2}
$$

The quadratic form of AR and its dependence on mean profits only are strong assumptions, which we discuss in the conclusion. The expected 'profit' is computed by multiplying estimated mean yields, $f($.$) , by output prices, p$, subtracting input costs for all three inputs (fertilizer, labor, water) and adding decoupled CAP subsidies, $s$ :

$$
\mu_{\pi}=p f(.)-\sum_{k} r_{k} x_{k}+s
$$

for $k=w, f, l$. Finally, the variance of expected profits is based on the value of the risk function, $g($.$) :$

$$
\sigma_{\pi}^{2}=p^{2} g(.)^{2} .
$$

We use full information maximum likelihood estimation (FIML), an approach to the estimation of simultaneous equations. One potential inconvenient of FIML estimation is that it assumes normally distributed residuals, assumption which is not needed by single equation methods, such as GMM. However, as shown in the literature, FIML is superior to single equation limited information methods, even if the model is severely misspecified and the measurement errors are non-normally distributed (see for example Fuhrer et al., 1995). Another advantage of FIML estimation is that it allows us not to instrument for endogenous inputs, for which we would need additional instrumental variables.

\section{Results}

\subsection{A simultaneous probit model of irrigation and insurance choice}

We now turn to the interpretation of the probit estimation in table 2. Let us first consider the coefficients linked to irrigation choice. Farmers are sensitive to past mean and variance of climate. The higher the previous year's water availability, the lower the probability the farmer will adopt irrigation technology. The higher the variance of water availability, the greater the probability the farmer will use irrigation. Farmers are not sensitive to the skewness of water availability when it comes to the choice of irrigation. But they are sensitive to the variance of income generated in the past: the more variable their income in the past, the greater the probability farmers will adopt irrigation technology. Irrigation is thus used as a tool to smooth farmers' income. This is in line with previous results in the literature (see Vandeveer et al., 1989; Koundouri et al., 2009).

Next, CAP subsidies have a positive impact on irrigation choice. In France, since 2006, CAP payments have been decoupled from production and, in addition, specific subsidies for irrigated land have been stopped. However, there is a memory effect as farmers who irrigated in the past continue to receive higher average CAP payments. Water price has 
Table 2: Probit estimates of irrigation and insurance choice

\begin{tabular}{|c|c|c|}
\hline & $\begin{array}{l}\text { Estimated } \\
\text { parameter }\end{array}$ & $\begin{array}{r}\text { Standard } \\
\text { error }\end{array}$ \\
\hline \multicolumn{3}{|l|}{ Probability to irrigate } \\
\hline Intercept & 1.038 & 1.552 \\
\hline Water availability in 2005 & $-0.018^{* *}$ & 0.006 \\
\hline Variance of water availability in 2005 & $0.080^{* *}$ & 0.040 \\
\hline Skewness of water availability in 2005 & -0.018 & 0.453 \\
\hline Intertemp. mean of income & -0.165 & 0.145 \\
\hline Intertemp. variance of income & $0.126^{* *}$ & 0.059 \\
\hline CAP subsidies & $0.541^{* *}$ & 0.209 \\
\hline Age & -0.033 & 0.022 \\
\hline Secondary education & $1.163^{*}$ & 0.656 \\
\hline Higher education & -0.167 & 0.865 \\
\hline Gender & $-2.377^{* *}$ & 0.855 \\
\hline Water price & $-27.814^{* *}$ & 4.851 \\
\hline Fertilizer price & 0.128 & 0.276 \\
\hline Labour price & $-0.021^{*}$ & 0.011 \\
\hline Yield Insurance & $-1.205^{* *}$ & 0.293 \\
\hline \multicolumn{3}{|l|}{ Probability to be insured } \\
\hline Intercept & 0.463 & 1.088 \\
\hline Water availability in 2005 & $-0.007^{* *}$ & 0.002 \\
\hline Variance of water availability in 2005 & $0.065^{* *}$ & 0.022 \\
\hline Skewness of water availability in 2005 & $-0.551^{* *}$ & 0.225 \\
\hline Intertemporal mean of income & 0.015 & 0.066 \\
\hline Intertemporal variance of income & 0.024 & 0.026 \\
\hline CAP subsidies & 0.159 & 0.101 \\
\hline Age & $-0.030^{* *}$ & 0.013 \\
\hline Secondary education & $0.897^{* *}$ & 0.385 \\
\hline Higher education & $1.294^{* *}$ & 0.451 \\
\hline Gender ( $1=$ being a male) & $-1.531^{* *}$ & 0.442 \\
\hline Water price & -1.409 & 1.818 \\
\hline Fertilizer price & 0.287 & 0.219 \\
\hline Labour price & 0.003 & 0.007 \\
\hline Loss ratio in 2005 & $0.899^{* *}$ & 0.184 \\
\hline
\end{tabular}

Note: Results obtained with STATA

$* * *, * *$ and $*$ denote significance at 1,5 and 10 per cent level respectively. 
a significant negative effect on irrigation choice: the more expensive the irrigation water, the lower the probability of becoming an irrigating farmer. Conversely, the price of labor input decreases the probability to irrigate (at the $10 \%$ level of significance.) This can be explained by the labor-intensity of irrigating agriculture. Secondary education increases the probability of becoming an irrigator (at the $10 \%$ level of significance). There is also a gender effect that is significant at the $5 \%$ level.

Finally, there is a direct and significant link between having yield insurance and adopting irrigation. Having opted for yield insurance significantly decreases the probability of adopting irrigation. This may indicate that yield insurance and irrigation could be substitutes. In that sense, irrigation can be considered as being a self-insurance tool.

The decision to buy yield insurance is sensitive to the previous year's water availability. The higher the water availability, the lower the probability of the farmer buying yield insurance. The higher the variance of water availability, the higher the probability of the farmer buying yield insurance ${ }^{14}$. With a higher educational level (compared to primary education), the probability of buying yield insurance is increased, both for secondary and higher education. Higher education favors the knowledge of risk management instruments such as yield insurance. On the other hand, the older the farmer, the lower his propensity to insure. There is also a gender effect: male farmers are more likely to buy insurance. Finally, the loss ratio in 2005 has a significant positive effect on buying yield insurance: the higher the previous year's loss ratio, the higher the probability of farmers buying yield insurance. This result is in line with results reported in the literature (see for example Garrido and Zilberman, 2008; Goodwin et al., 2004). Higher loss ratios indicate that the investment in insurance is profitable, which explains this result.

The main conclusion of this simultaneous probit estimation is that irrigation choice is sensitive to the variability of both climatic and economic variables. It is also sensitive to the presence of subsidy payments and yield insurance. This suggests that farmers may adopt irrigation to reduce their production risk. We took these factors into account in the following estimation step where we focus on the volume of irrigation water that is used in the production process.

\subsection{Joint estimation of production and risk preference parameters}

Table 3 shows the results of the joint estimation of production and risk preference parameters. All linear and squared terms of the mean yield function have significant coefficients at the $5 \%$ level. For labor input, the direct marginal effect is positive and the squared term is negative. This suggests that there are decreasing returns to scale for the use of labor. For water and fertilizer, the direct marginal effect is negative and the squared term is positive. This suggests increasing returns to scale. All crossed effects are positive which means that inputs are complementary.

\footnotetext{
${ }^{14}$ The asymmetric distribution of water, in favor of less negative areas, encourages the farmer to refrain from buying yield insurance.
} 
Table 3: Estimation results ${ }^{\S}$

\begin{tabular}{|c|c|c|c|}
\hline Parameter & Variable & $\begin{array}{c}\text { Estimated } \\
\text { coefficient }\end{array}$ & $\begin{array}{r}\text { Standard } \\
\text { error }\end{array}$ \\
\hline \multicolumn{4}{|c|}{ Mean yield function } \\
\hline$\alpha_{w}$ & water & $-0.0089^{* *}$ & 0.0027 \\
\hline$\alpha_{w w}$ & water*water & $0.0000^{* *}$ & 0.0000 \\
\hline$\alpha_{f}$ & fertilizer & $-0.2129^{* *}$ & 0.0683 \\
\hline$\alpha_{f f}$ & fertilizer*fertilizer & $0.0018^{* *}$ & 0.0004 \\
\hline$\alpha_{l}$ & labour & $3.1217^{* *}$ & 0.1618 \\
\hline$\alpha_{l l}$ & labour*labour & $-0.0373^{* *}$ & 0.0024 \\
\hline$\alpha_{w f}$ & water*fertilizer & $0.0000^{*}$ & 0.0000 \\
\hline$\alpha_{w l}$ & water*labour & $0.0001^{* *}$ & 0.0000 \\
\hline$\alpha_{f l}$ & fertilizer*labour & $0.0021^{* *}$ & 0.0004 \\
\hline$\sigma_{u}$ & inverse mills ratio & $51.151^{* *}$ & 13.334 \\
\hline
\end{tabular}

Risk production function

$\begin{array}{rrrr}\beta_{w} & \text { water } & 0.3242^{* *} & 0.0180 \\ \beta_{f} & \text { fertilizer } & 0.2658^{* *} & 0.0445 \\ \beta_{l} & \text { labour } & 0.4356^{* *} & 0.0700\end{array}$

AR function

\begin{tabular}{ccc}
$\delta_{0}$ & -0.0038 & 0.0034 \\
$\delta_{1}$ & $0.0232^{* *}$ & 0.0115 \\
$\delta_{2}$ & $-0.0167^{*}$ & 0.0090 \\
$\gamma$ & $-0.2746^{* *}$ & 0.1381 \\
\hline
\end{tabular}

$\S$ FIML estimation. 165 observations. Results obtained with SAS. $* * *, * *$ and $*$ denote significance at 1,5 and 10 per cent level respectively. 
All three inputs have a significant positive impact on the variance of yields (as indicated by the coefficients of the risk function), at conventional statistical confidence levels. Using more water volumes thus increases the variability of yields. This is in line with Just and Pope (1979), who found that fertilizers increased mean yield but also significantly increased the variance of yield. Table 3 also shows the estimated coefficient associated with the inverse Mill's ratio, which is significant. This means that the correction for the sample selection bias was necessary. Finally, table 3 lists the parameters of the risk function, which are all significant, and were used to compute the Arrow-Pratt risk aversion coefficient.

Table 4: Expected profit, elasticities and risk preference estimations

\begin{tabular}{|c|c|c|}
\hline & Mean & $\begin{array}{l}\text { Standard } \\
\text { deviation }\end{array}$ \\
\hline \multicolumn{3}{|c|}{ Expected Profit } \\
\hline$\mu_{\pi}$ & 0.9187 & 0.7374 \\
\hline$\sigma_{\mu_{\pi}}$ & 2.4164 & 1.2327 \\
\hline \multicolumn{3}{|c|}{ Elasticities wrt mean function } \\
\hline$\xi_{x w}$ & 0.0457 & 0.2158 \\
\hline$\xi_{x f}$ & 0.1525 & 0.2430 \\
\hline$\xi_{x l}$ & 0.6480 & 1.4940 \\
\hline \multicolumn{3}{|c|}{ Risk preferences and attitudes } \\
\hline $\mathrm{AR}$ & 0.0060 & 0.0124 \\
\hline DR & -0.0077 & 0.0119 \\
\hline$\theta$ & -0.0205 & 0.0982 \\
\hline RRP & 0.0001 & 0.0004 \\
\hline
\end{tabular}

Table 4 indicates mean and variance of estimated profits, including CAP subsidies. The expected profit of our population is equal to 918.7 euros/ha (compared to 1020 euros/ha when computed with observed yields). Table 4 also indicates the elasticity of inputs: the elasticity of input $x$ on the mean part of the yield function, $f$, is given by : $\xi_{x} \equiv$ $\frac{\partial f}{\partial x} \frac{x}{f}$. We computed elasticities for each individual farm, and then we computed mean and standard deviation of the sample. On average, all inputs have a positive marginal impact on mean yield. A $1 \%$ increase in irrigation water increases mean yields by $0.05 \%$ on average. Likewise, a $1 \%$ increase in fertilizer (labor) increases the mean yields by $0.15 \%$ $(0.65 \%)$ on average. ${ }^{15}$

\footnotetext{
${ }^{15}$ Note that standard deviations are large, i.e. there are some farms for which the elasticity has the
} 
Figure 2: Arrow-Pratt coefficient as a function of expected profits

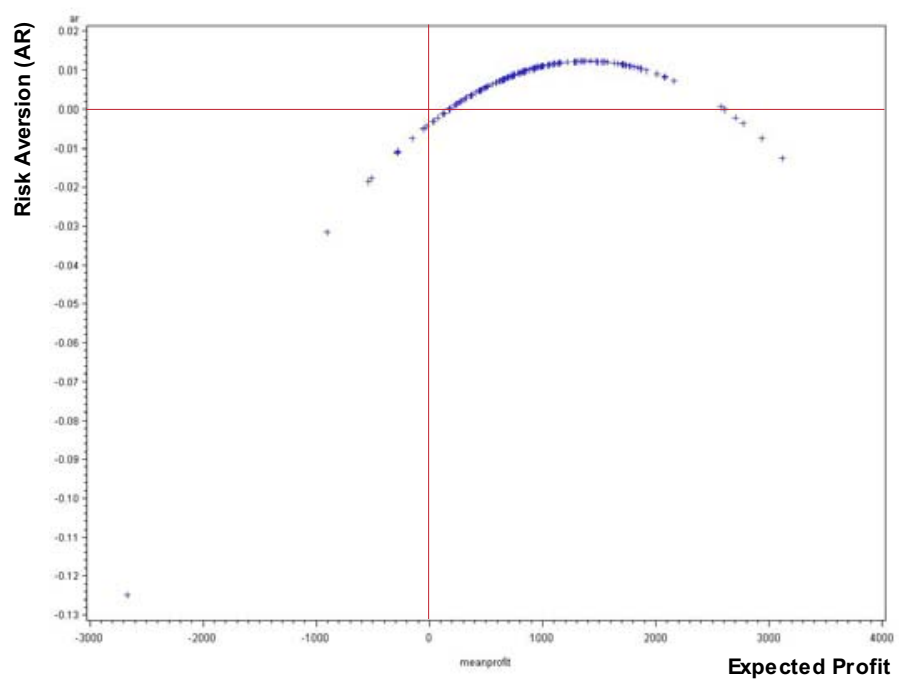

Finally, table 4 shows the risk preferences that can be derived from the above estimation results. We can see that $\theta$ is negative $(-0.02)$ which means that irrigating farmers are risk averse. The mean Arrow-Pratt (AR) coefficient is positive, which indicates risk aversion, but close to zero $(\mathrm{AR}=0.006)$ which means that risk preferences are quite close to risk neutrality. It is interesting to plot the individual AR points as a function of expected profits (see figure 2). We can see that most corn growers display a very slight risk aversion, except for those who generate either very high profits $\left(\mu_{\pi}>2600\right)$ or very low profits $\left(\mu_{\pi}<200\right)$, these farmers being risk lovers. The downside-risk coefficient is negative, which means that farmers are averse to extreme profiles of the profit function, especially to big losses. Finally, we can also interpret the relative risk premium, RRP, which represents the percentage of wealth that the farmer is willing to pay to avoid taking additional risks. In our case, the average farmer is willing to pay $0.01 \%$ of his mean profit, i.e. $0.09 €$. This may confirm that preferences are close to risk neutrality. In contrast to earlier studies, and following Lence (2009) and Just and Just (2011), we do not interpret the agent's type of risk aversion, i.e. whether they exhibit increasing, decreasing or constant risk aversion, because it cannot be robustly derived from this type of model.

Most previous studies in the literature reported risk aversion. However, there is only one study that considers irrigating farmers: Groom et al. (2008) found a mean Arrow-Pratt coefficient of 0.34 for cereal growers and 0.072 for vegetable growers in Cyprus. Reynaud (2009) suggests using Arrow-Pratt coefficients between -2 and +2 for irrigating cereal

opposite sign. For example, for fertilizer use, $10 \%$ of the sample has a negative elasticity. 
Author-produced version of the article published in European Review of Agricultural Economics, 2011,39(3), 439-457. doi: 10.1093/erae/jbr024

Figure 3: Distribution of observed profits for non-irrigating (0) and irrigating (1) farmers

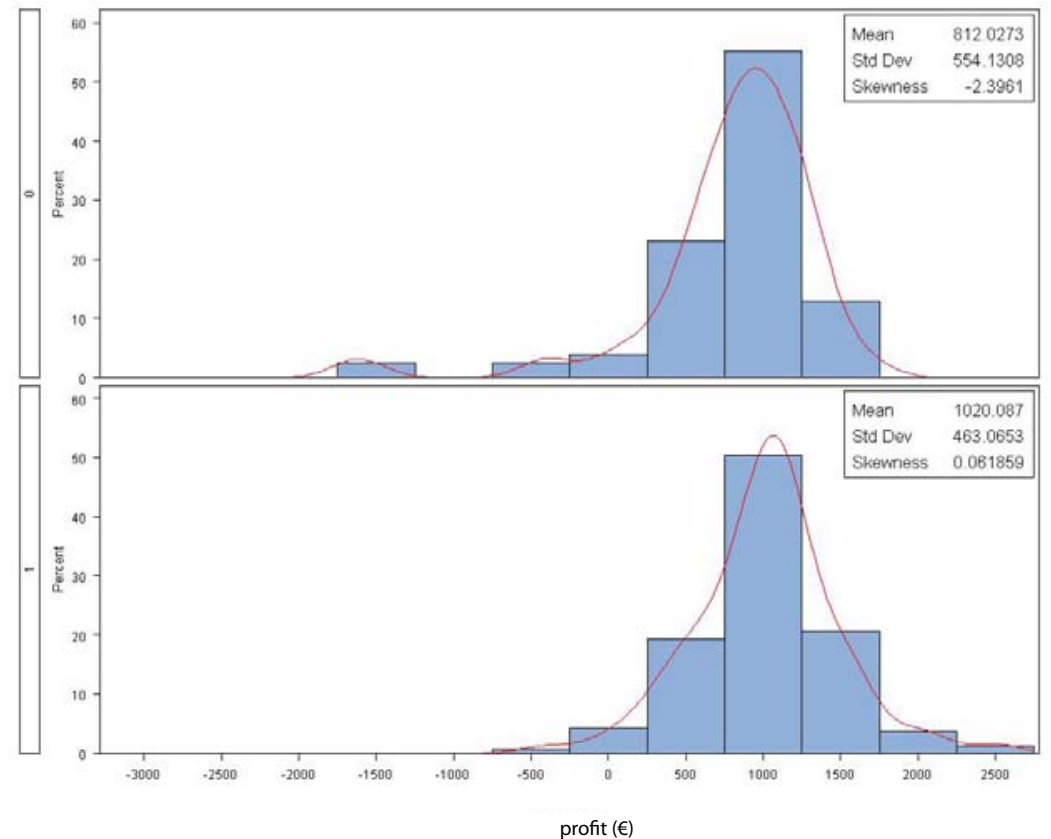

Figure 4: Distribution of estimated profits for non-irrigating (0) and irrigating (1) farmers

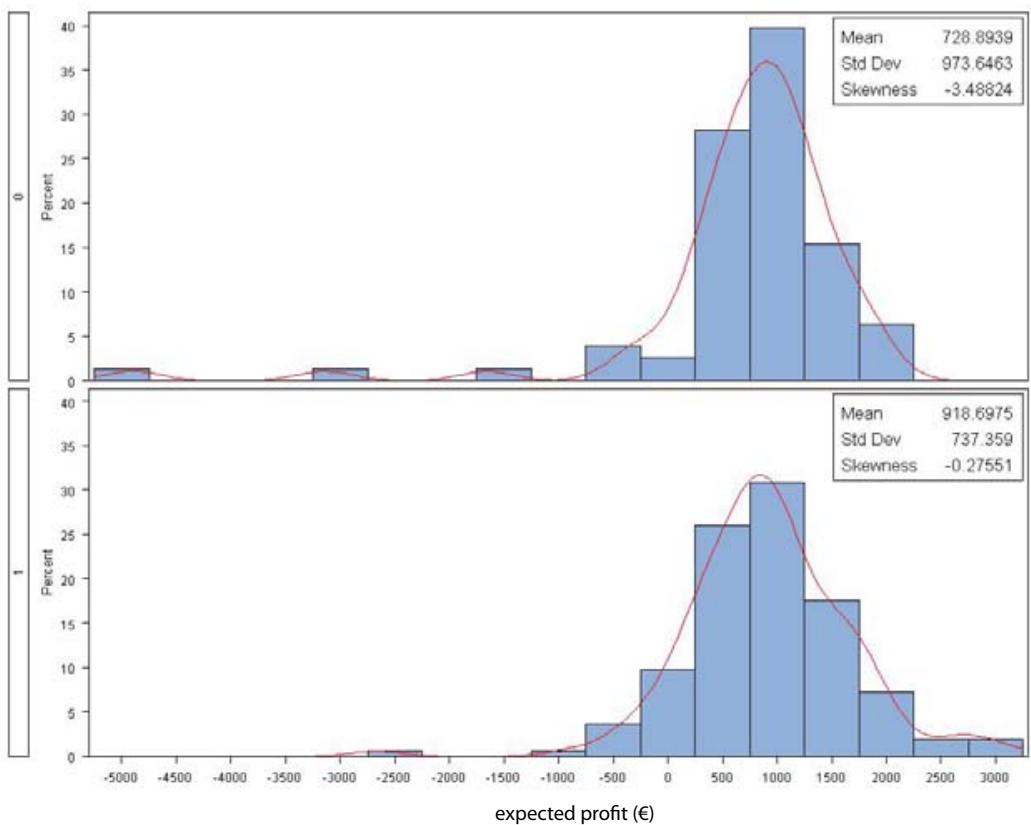


growers, but without performing any estimation. Our Arrow-Pratt values are very low, indicating a very small risk aversion, but they are within this proposed range of results. We may explain the small risk aversion by the fact that we consider CAP subsidies as one element of farmers' revenues. CAP earnings constitute a stable part of earnings and tend to decrease risk aversion, as also shown in Koundouri et al. (2009). CAP subsidies account for over $50 \%$ of total expected profits in our sample.

Finally, we can compare the distribution of profits for irrigating and non-irrigating farmers, both in the initial dataset (with $y$ as yield) and in our estimated dataset (with $f($.$) as yield). Figure 3$ shows the distribution of profits in the observed dataset. We can see that non-irrigating farmers have a lower mean and a higher variance than irrigating farmers. They also have a negative skewness whereas the distribution for irrigating farmers is right-skewed: irrigating farmers make fewer big losses. This profile was confirmed after our joint estimation procedure: irrigating farmers' profits $(\mu)$ are higher than those of non-irrigating farmers, variance is smaller and skewness is less negative, as shown in figure 4). Thus, we show that irrigation decreases the variance of profits ${ }^{16}$.

\section{Concluding remarks}

In this paper, we studied the role of farmers' input decisions in the management of production risk and focused on the role of irrigation as a possible self-insurance tool. We found that a farmer's decision whether to irrigate (or not) depends on his decision to purchase yield insurance (or not). Yield insurance decreases the probability of adopting irrigation. The introduction of a yield insurance policy, such as the one set up in France in 2005, may thus lead to a reduction in the overall use of agricultural water, which might be an interesting side-effect for policy making.

We also analyzed the impact of irrigation water use in the production process of irrigating farmers. As expected, we confirm that irrigation increases mean yields and profits. But using more volumes of irrigation water when already being an irrigator increases the variance of yields (at least for risk-averse farmers). The insurance dimension of irrigation is thus restricted. This result may be due to the fact that in 2006 and 2007 the need for water was not very large in the French agricultural sector, compared to the four previous years. It would be interesting to replicate this study in a country with dryer climate where variability of yield should be greater.

Finally, when it comes to the impact of irrigation on profits, we showed that irrigating farmers have higher means, lower variances and less negative skewness than non-irrigating farmers. This result may be explained by the fact that irrigation increases the quality of production and opens new markets, at higher prices. It appears thus that it is worth investing in irrigation technology because this improves the overall profile of the profit

\footnotetext{
${ }^{16}$ The fact that there are some negative outliers in our estimated results might indicate underestimation of the mean yield, $f($.$) . It might also be due to the fact that in our estimated dataset, farmers who make$ losses are risk lovers, which may encourage them to adopt even more extreme production behavior.
} 
distributions.

We are aware that the most recent literature sheds serious doubts on the validity of the methodology adopted in this paper for estimating risk attitudes (see Lence, 2009; Just, 2008; Just and Just, 2011; Just and Peterson, 2010). In particular, Just and Just (2011) showed that 'many specifications of risk preferences paired with particular specifications of [...] production risk, or production structure fit behavioral equations with a given revealed preference dataset equally well, regardless of the number of observations'. They conclude that global identification of risk preferences and risk from the estimation of behavioral equations alone is impossible. Just (2008) concludes that the above approach is therefore insufficient for normative policy analysis. In our case, and following the previous literature, we have assumed the AR function to be quadratic. The results we report are only valid under this assumption. We cannot exclude that other results are possible for other specifications. But as pointed out by Just and Just (2011), the joint estimation method cannot overcome the problem of misspecification as misspecification tests are invalidated. Hence, we cannot give normative policy advice. We also restrain the AR function to depend on mean profits only, which is again a strong assumption, because risk preferences may also depend on other drivers (see Just, 2011). Finally, Just and Peterson (2010) argue that such estimation problems in many empirical applications may stem from the wrong assumption of expected utility theory (EUT). They show this for the joint estimation method proposed by Love and Buccola (1991). Our paper is clearly embedded in the framework of EUT, assuming maximization of expected utility to be a good benchmark behaviour for a representative farmer.

In further work, it would be interesting to compare the above approach with the upcoming estimation methods for risk and preferences, including those considering non-expected utility theory. Concerning our specific topic, it would be interesting to gain more insight into the possible complementarities of irrigation and other insurance tools. The issue of complementarity is only very imperfectly addressed by our model. We could also analyze a broader population, for example less specialized producers. This means that the non-jointness assumption would no longer hold and would imply the need for different assumptions on the distribution of production costs and the interactions between different types of production. Finally, another interesting point would be to try to integrate skewness into an estimation framework of risk preferences and production decisions. This implies re-thinking the way the risk-aversion coefficient is computed and constitutes another possible line of future research.

\section{Acknoledgements}

The authors acknowledge financial support from the ANR RISECO project ANR-08-JCJC0074-01. In addition, Sébastien Foudi acknowledges financial support from Cemagref. We are grateful to Alban Thomas and Celine Nauges who provided helpful comments at many stages of the work and to Julien Lerat and Vazken Andreassian for advice on the 
meteorological data. We also thank the members of the French Agricultural Ministry, the INSEE and Meteo France, for providing the dataset.

\section{References}

Amadieu, P. and Viviani, J.-P. (2011). Intangible expenses: a solution to increase the French wine industry performance? European Review of Agricultural Economics doi:10.1093/erae/jbr012.

Amigues, J.P., Debaeke, P., Itier, B., Lemaire, G., Seguin, B., Tardieu, F. and Thomas, A. (2006). Sécheresse et agriculture. Réduire la vulnérabilité de l'agriculture à un risque accru de manque d'eau. Expertise scientifique collective, INRA, MEDAD. France.

Antle, J.M. (1983). Testing the stochastic structure of production: A flexible moment based approach. Journal of Business and Economic Statistics 1: 192-201.

Antle, J.M. (1987). Econometric estimation of producer's risk attitudes. American Journal of Agricultural Economics 69: 509-522.

Antle, J.M. (1988). Pesticides policy, production risk, and producer welfare. An econometric approach to applied welfare economics. Eds. Resource For the Future.

Antle, J.M. and Goodger, W.J. (1984). Measuring stochastic technology: The case of Tulare milk production. American Journal of Agricultural Economics 66: 342-350.

Di Falco, S. and Chavas, J.-P. (2006). Crop genetic diversity, farm productivity and the management of environmental risk in rainfed agriculture. European Review of Agricultural Economics 33: 289-314.

Eggert, H. and Tveteras, R. (2004). Stochastic production and heterogeneous risk preferences: Commercial fisher's gear choices. American Journal of Agricultural Economics 86: $199-212$.

Fuhrer, J.C., Moore, G.R. and Schuh, S.D. (1995). Estimating the linear-quadratic inventory model: Maximum Likelihood versus Generalized Method of Moments. Journal of Monetary Economics 35: 115-157.

Garrido, A. and Zilberman, D. (2008). Revisiting the demand of agricultural insurance: The case of Spain. Agricultural Finance Review 68: 43-66.

Goodwin, B., Vandeveer, M.L. and Deal, J.L. (2004). An empirical analysis of acreage effects of participation in the federal crop insurance program. American Journal of Agricultural Economics 86: 1058-1077. 
Groom, B., Koundouri, P., Nauges, C. and Thomas, A. (2008). The story of the moment: Risk averse Cypriot farmers respond to drought management. Applied Economics 40: $315-326$.

Henessy, D.A. (1998). The production effects of agricultural income support policies under uncertainty. American Journal of Agricultural Economics 80: 46-57.

Isik, M. (2002). Resource management under production and output price uncertainty: Implications for environmental policy. American Journal of Agricultural Ecnomics 84: $557-571$.

Just, D.R. (2011). Calibrating the wealth effects of decoupled payments: Does decreasing absolute risk aversion matter? Journal of Econometrics 162: 25-34.

Just, D.R. and Peterson, H.H. (2010). Is expected utility theory applicable? A revealed preference test. American Journal of Agricultural Ecnomics 92: 16-27.

Just, R.E. (2008). Distinguishing preferences from perceptions for meaningful policy analysis. American Journal of Agricultural Ecnomics 90: 1165-1175.

Just, R.E. and Just, D.R. (2011). Global identification of risk preferences with revealed preference data. Journal of Econometrics 162: 6-17.

Just, R.E. and Pope, R.D. (1978). Stochastic specification of production functions and economic implications. Journal of Econometrics 7: 67-86.

Just, R.E. and Pope, R.D. (1979). Production function estimation and related risk considerations. American Journal of Agricultural Ecnomics 61: 276-284.

Koundouri, P., Nauges, C. and Tzouvelekas, V. (2006). Technology adoption under production uncertainty: Theory and application to irrigation technology. American Journal of Agricultural Ecnomics 88: 657-670.

Koundouri, P., Laukkanen, M., Myrrä, S. and Nauges, C. (2009). EU agricultural policy change: Effects on farmer's risk attitudes. European Review of Agricultural Economics 36: $53-77$.

Kumbhakar, S.C. and Tveteras, R. (2003). Risk preferences, production risk and firm heterogeneity. Scandinavian Journal of Economics 105: 275-293.

Lence, S. (2009). Joint estimation of risk preferences and technology: Flexible utility or futility? American Journal of Agricultural Economics 91: 581-598.

Love, H.A. and Buccola, S.T. (1991). Joint risk preference-technology estimation with a primal system. American Journal of Agricultural Economics 73: 765-774. 
Love, H.A. and Buccola, S.T. (1999). Joint risk preference-technology estimation with a primal system: Reply. American Journal of Agricultural Economics 81: 245-247.

Maddala, G.S. (1983). Limited-Dependent and Qualitative Variables in Econometrics. Cambridge University Press.

Reynaud, A. (2009). Adaptation à court et à long terme de l'agriculture au risque de sécheresse : une approche par couplage de modèles biophysiques et économiques. Review of Agricultural and Environmental Studies 90: 121-154.

Shankar, B. and Nelson, C.H. (1999). Joint risk preference-technology estimation with a primal system: Comment. American Journal of Agricultural Economics 81: 241-244.

Vandeveer, L.R., Paxton, K.W. and Lavergne, D.R. (1989). Irrigation and potential diversification benefits in humid climats. Southern Journal of Agricultural Economics 21: $167-174$.

Zellner, A., Kmenta, J. and Dreze, J. (1966). Specification and estimation of Cobb-Douglas production function models. Econometrica 34: 784-795. 